\title{
Careerism in Radiology
}

\author{
Richard B. Gunderman MD, $\mathrm{PhD}{ }^{\text {a }}$
}

Frank J. Lexa MD, MBA ${ }^{b}$

${ }^{a}$ Department of Radiology, Indiana University, Indianapolis, Indiana

${ }^{\mathrm{b}}$ Wharton School of Business, University of Pennsylvania, Philadelphia, Pennsylvania

“In order to move up, you must move laterally.” This piece of advice was first shared with us early in our careers and often since. Taken at face value, it means that if you want to get promoted quickly and move up the echelons of the organization chart of a radiology department, hospital, medical school, or health system, you must be prepared to move from organization to organization, negotiating for promotions at each transition.

This attitude, common in the corporate world, has infected a large part of the radiology community, particularly its more ambitious denizens. We know of people who, after moving from one institution to another, often wait only a year or two before they start circulating their curricula vitae in hopes of moving on to an even greener pasture. If you listen to them when they are being candid about their careers, they view each organization as a stepping-stone to a yet higher station.

Unfortunately, this kind of self-interested careerism takes a toll not only on the organizations at which these individuals spend a few years before moving onward and upward, but also on the careerists themselves, many of whom are unable to find any real satisfaction in the roles they play at any particular time. They are so busy planning their next move that, except for burnishing their curricula vitae, they pay relatively little attention to the culture they are working in and the people who inhabit it.

This is the author's manuscript of the article published in final edited form as:

Gunderman, R. B., \& Lexa, F. J. (2018). Careerism in Radiology. Journal of the American College of Radiology, 15(1, Part A), 125-127. https://doi.org/10.1016/j.jacr.2017.05.011 
The first problem with this careerist attitude is the implicit assumption that you can gauge the quality or importance of the work someone does by the title they hold. On this assumption, a dean is more important than a department chair, a department chair is more important than a full professor, a full professor is more important than an associate professor, and so on. In fact, however, titles provide little insight into the quality or importance of the work people do.

It is infrequent that the most important work in an organization is being done by the chief administrators, and this is especially true of the organizations in which particularly deep, complicated, and innovative work is being done. Administrators spend a great deal of their time administrating, which leaves relatively little time for truly creative work. It is important that good people serve in these roles, but this is largely because it minimizes the harm that bad administration would do.

The same can be said of academic rank. Often the most important work in a department is done not by the most senior faculty members, but by those at more junior stages of their careers. They often see things with the freshest eyes and, because of a combination of promotion and tenure policies and a desire to make their mark, they often feel the strongest urge to produce something of note in a short period of time.

Another problem with the careerist perspective is the damage it can inflict on the organizations through which careerists pass. Because careerists have no real interest or loyalty toward the people or culture they work with at any particular time - they are prepared to leave the moment a better opportunity comes along - they tend to devote the bulk of their attention to things they can easily detach from, the sorts of things that are often taught in schools of management.

For example, careerists have often pursued advanced management training such as a master's of business administration (MBA) degree relatively early in their career, thinking that by learning accounting, finance, and strategic planning, they will rapidly be able to add value to any organization they join. They think that management is a "science” that they can learn just like chemistry and that its 
principles apply invariably across the board in every organization. This is a simplistic approach to adding real value.

In fact, however, every institution is different from every other. Each organization has its own traditions, aspirations, and people. An organization is not just a machine composed of interchangeable parts. It is also an organism, with its own heart and soul. To serve the organization effectively, it is necessary not only to take charge of it but to know it. To suppose that every radiology department, hospital, or medical school is fundamentally the same is to fail to know what they really are.

Such careerists, particularly those with advanced training in management, will often speak in very analytic terms, waxing eloquent about the need for “metrics,” developing more robust “measures,” and holding people accountable for "meeting their numbers.” They love to talk about the "bottom line.” Partly by birth and partly by training, they come to see the world itself and the organizations and people who make it up as primarily quantitative phenomena.

The problem, of course, is that many features of an organization resist quantification-most prominently, the people who make up the organization. Because the careerist is so keen to make numbers and improve the bottom line, an organization led by a careerist tends to become increasingly focused on metrics and increasingly blind to people. The organization begins putting other things before people, and when this happens, it begins to use rather than care about its most precious resource.

A similar shift takes place with respect to temporal outlook. Because the careerist does not intend to be around for long — and in fact, remaining on site for more than 3 to 5 years would seem a sign of failure - the organization begins to think on a time horizon of a few years or even months. The emphasis is on getting results now. When this happens, the organization begins chewing up the people who make it up, in effect consuming its seed corn.

The antidote to careerism is simple in theory but difficult to implement in practice. The first step in turning things around is to recognize the importance of deep knowledge about an organization, its 
people, and its relationships with other organizations. No one can learn in a year or 18 months what it takes to serve an organization effectively as a leader. The key qualification is not an academic degree but substantial real-world experience within the organization.

This is one of the most important problems with MBA programs. The presumption is that they can teach a skill set that can be transferred easily from sector to sector, culture to culture, and organization to organization. In fact, however, many graduates of the nation's top MBA programs do not go on to serve any particular organization for a long period of time. Instead, they go into consulting, moving from organization to organization every few months or years and never attaining deep knowledge.

They are immersed in a kind of stranger leadership, one premised on the misguided notion that everything important to know about an organization can be gleaned from extensive data acquisition and analysis. Yet people and relationships cannot be adequately described, let alone understood, in purely analytic terms. To know people, relationships, and organizations deeply, there is no substitute for the experience born only of dedication.

Many MBA-toting careerists have been brought up on a steady diet of cases. They think that because they have read two dozen pages describing a real-world business situation, they know what realworld business is like. In fact, however, most case studies are written by business school professors who have an ax to grind. Moreover, such case studies almost never provide a rich description of what it is like to work in the organization and what the organization really stands for.

For example, business school case studies tend to portray reality in economic terms, when in fact economics is only a small part of the life of any organization, including a business. People come to work to make money, but many other reasons are also in play, such as the desire to build collegial relationships, do challenging work, grow as a professional and a person, and make a difference in the community. A narrow focus on economics naturally augments careerism. 
Careerists can be difficult to spot, but there is one sure sign. Even though they know they should not, they will soon begin describing the organization's situation as a crisis and outlining their own solutions in revolutionary terms. The implicit assumption? The organization is crashing and needs someone to rescue it from disaster. Only when people believe the organization is doing fundamentally good work will the opportunities for careerism remain sufficiently circumscribed.

To fix the problem, we need to thoroughly examine the benefits, risks, and costs of itinerant leadership, and in particular the toll taken by leaders who have no enduring commitment to either the organization or its people. Being a physician and successfully contributing to organizations and communities requires a level and length of commitment that is inconsistent with the careerist's short game. We need more people who operate with a wider, deeper, and longer-term commitment. 